\title{
PENGARUH GAYA POTONG PEMBUBUTAN TERHADAP KEAUSAN PAHAT KARBIDA COATED PADA BENDA KERJA BAJA AISI 4340
}

\author{
Rosehan $^{1)}$, M. Sobron Y. Lubis ${ }^{2)}$ dan Dellica Chandra ${ }^{3)}$ \\ ${ }^{1,2)}$ Program Studi Teknik Mesin Fakultas Teknik Universitas Tarumanagara \\ ${ }^{3)}$ Mahasiswa Teknik Mesin Fakultas Teknik Universitas Tarumanagara \\ e-mail: ${ }^{1)}$ rosehan@ft.untar.ac.id ; ${ }^{2}$ sobronl@ft.untar.ac.id ; ${ }^{3)}$ dellica.515130026@stu.untar.ac.id;
}

\begin{abstract}
Cutting force and tool life is the important data in planning a machining process. The research is in order to describe about the influence of the cutting force to the tool wear on carbide coated cutting tools used the turning process of an alloy steel of AISI 4340. The research was conducted by observing the growth of tool wear on minutes 4.5, 9, 13.5, 18, 22.5 with the maximum value VB $0.3 \mathrm{~mm}$, at the same time, the condition of other cutting such as the motion while the cutting, the depth and speed of the cutting movement was constant. The purpose of this experiment is to examine scientifically the influence cutting force to the growth of tool wear on carbide coated while the cutting process of alloy steel AISI 4340. The graphical method was used for the trial analysis, to see the cutting force comparison with the decrease of tool life of the carbide coated, and the correlation of the cutting movement with the cutting force. The mechanism decrease showed the adhesion decrease.
\end{abstract}

Keywords: cutting force, cutting tools, turning, alloy steel

\section{PENDAHULUAN}

Perkembangan material pada bidang teknik terutama komponen-komponen mesin untuk mampu menerima beban dinamis pada kecepatan tinggi, sehingga diperlukan ketahanan terhadap temperatur yang tinggi serta kekerasan yang tinggi. Pada saat proses pemesinan berlangsung, pahat akan mengalami gesekan dengan benda kerja dan benda kerja akan terpotong, sehingga terjadi interaksi antara pahat dengan benda kerja.

Salah satu bagian terpenting dari pemotongan adalah pahat bubut yang berperan penting dalam menentukan hasil permukaan dari proses pembubutan itu baik atau tidak, yaitu proses keausan pahat. Penelitian ini untuk melihat pengaruh gaya potong terhadap keausan mata pahat untuk mengetahui korelasi dari gaya potong dan keausan mata pahat.

Pada penelitian ini digunakan mata pahat coated carbide untuk melakukan proses bubut terhadap baja AISI 4340 yang tidak menggunakan coolant dengan kecepatan potong yang divariasikan dan laju pemakanan dan kedalaman potong yang konstan.

\section{METODOLOGI PENELITIAN}

Penelitian ini bertujuan untuk melihat pengaruh gaya potong pembubutan terhadap keausan pahat karbida coated pada benda kerja baja AISI 4340. Penelitian ini terdiri dari tiga tahap percobaan, yaitu:

1. Percobaan pertama, melakukan proses pembubutan memanjang dengan parameter, kedalam potong $\left(a_{p}\right)$ dan gerak makan $\left(f_{n}\right)$ konstan sedangkan kecepatan potong $\left(V_{c}\right)$ bervariasi.

2. Percobaan kedua, melakukan analisis terhadap data yang diperoleh dari hasil luaran berupa gaya potong.

3. Percobaan ketiga, melakukan pengukuran keausan mata pahat.

Langkah-langkah skematik penelitian pada Gambar 1. 


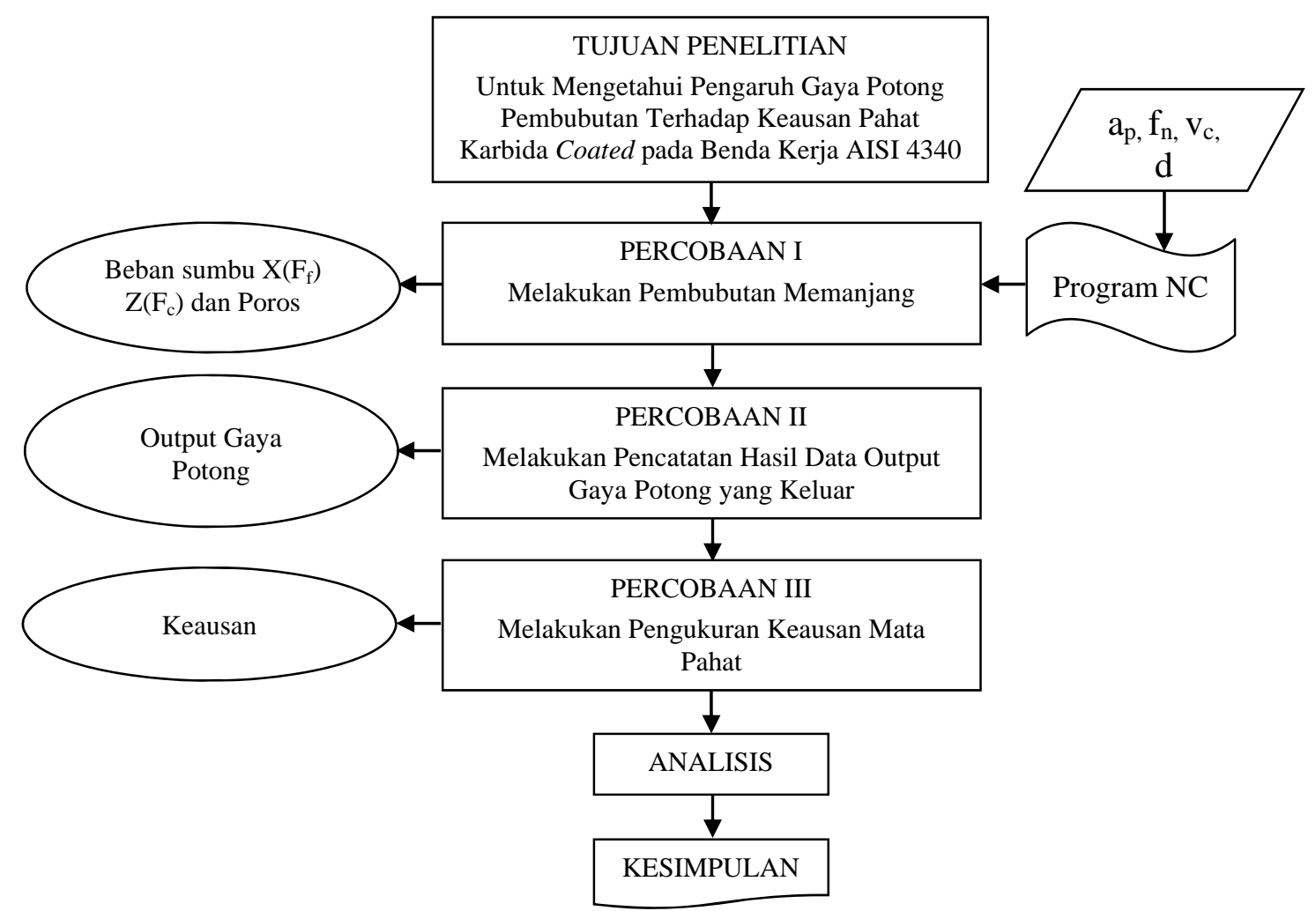

Gambar 1. Skema langkah-langkah penelitian

Peralatan yang digunakan dalam penelitian ini adalah sebagai berikut:

1. Mesin bubut CNC,

Mesin bubut ini digunakan untuk penelitian dengan tipe Mazak ICK Turn 8N

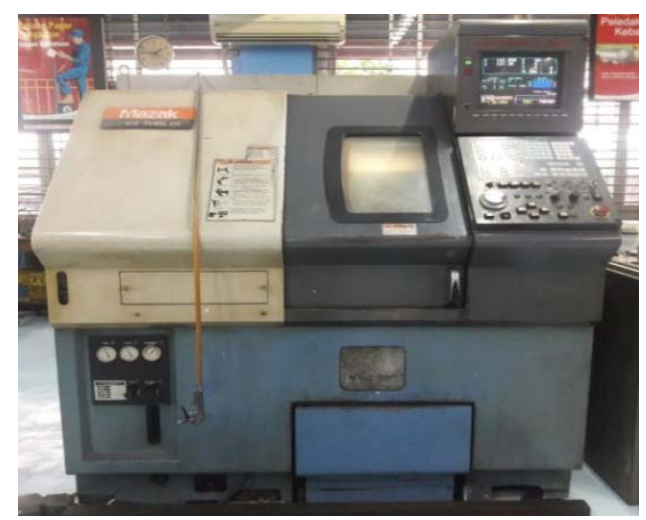

Gambar 2. Mesin CNC Milling

2. Insert karbida coated, kode TNMG 120408-GN new grade IC 3028, Insert untuk membubut material benda kerja pada penelitian ini

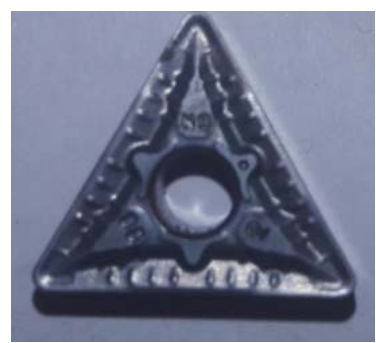

Gambar 3. Karbida TNMG 160408 


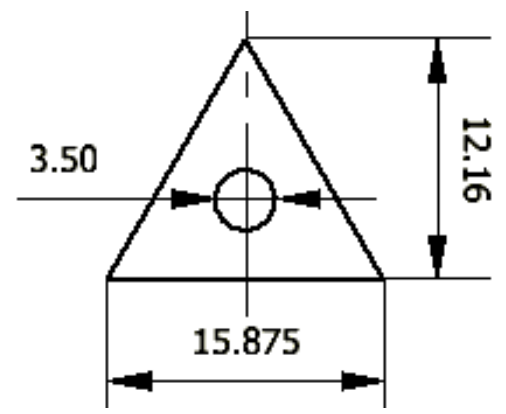

Gambar 4. Gambar teknik pahat karbida coated

3. Display Dynamometer

Alat ukur untuk melihat output gaya potong yaitu display force dynamometer,

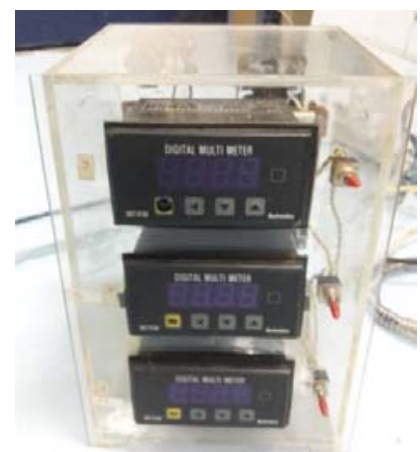

Gambar 5. Display dynamometer

4. Mikroskop Digital Jenco dan Komputer,

Untuk mengukur keausan tepi dari mata pahat

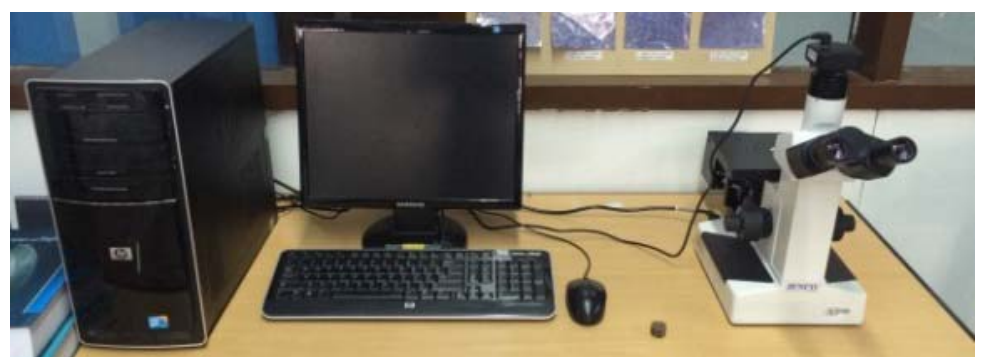

Gambar 6. Mikroskop Digital Jenco dan komputer

5. Material benda kerja,

Benda kerja yang digunakan adalah baja AISI 4340

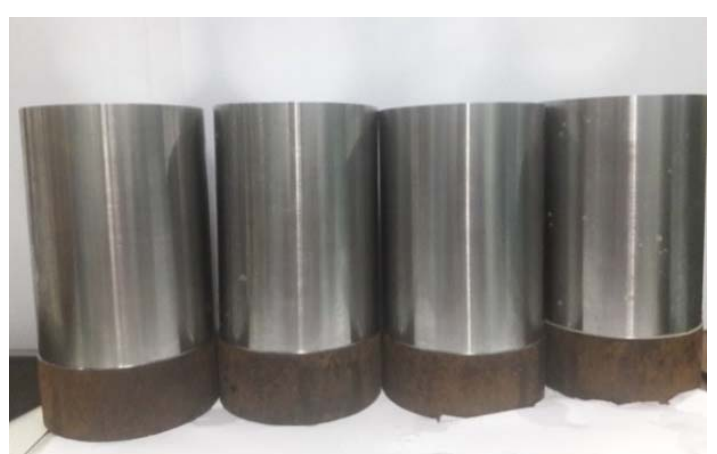

Gambar 7. Baja AISI 4340 
Data percobaan ada dua kelompok terdiri dari pembacaan pada kontrol mesin saat proses pemesinan berlangsung yaitu pengambilan data luaran gaya potong saat proses pemesinan berlangsung, dan insert dikeluarkan dari tool holder pada saat proses pemesinan sudah selesai berlangsung.

Pada penelitian ini dilakukan sebanyak lima kali percobaan pada satu benda kerja untuk setiap tingkat kecepatan potong dengan pengukuran sampel yang dilakukan sebanyak sembilan kali. Percobaan ini dilakukan sebanyak lima buah benda kerja dengan langkah kerja yang sama untuk memperjelas data.

Proses pemesinan dilakukan dengan kecepatan potong $160 \mathrm{~m} / \mathrm{min}$, dilakukan pembubutan sebanyak sembilan kali, kemudian, dilakukan hal yang sama dengan benda kerja yang kedua dan menggunakan insert yang sama. Proses pemesinan dilakukan sampai benda kerja kelima dengan insert yang sama. Selanjutnya, kembali melakukan proses pemesinan dimulai dari benda kerja pertama dengan insert yang kedua dan dilakukan dengan menurunkan kecepatan potong $\left(V_{c}\right)$ menjadi $140 \mathrm{~m} / \mathrm{min}$. Hal ini dilakukan sampai dengan benda kerja kelima dengan insert kedua dan kecepatan potong $140 \mathrm{~m} /$ min kemudian, setiap penurunan diameter $9 \mathrm{~mm}$ kecepatan potong di turunkan $20 \mathrm{~m} / \mathrm{min}$ untuk selanjutnya dan proses pemesinan dilakukan hal yang sama sampai dengan benda kerja kelima dan insert kelima dengan kecepatan potong $80 \mathrm{~m} / \mathrm{min}$.

Setiap kali proses pemesinan berakhir pada sembilan kali pemakanan dilakukan proses pengukuran keausan insert untuk mengetahui nilai keausan terjadi, sehingga didapatkan data untuk mencari nilai keausan insert.

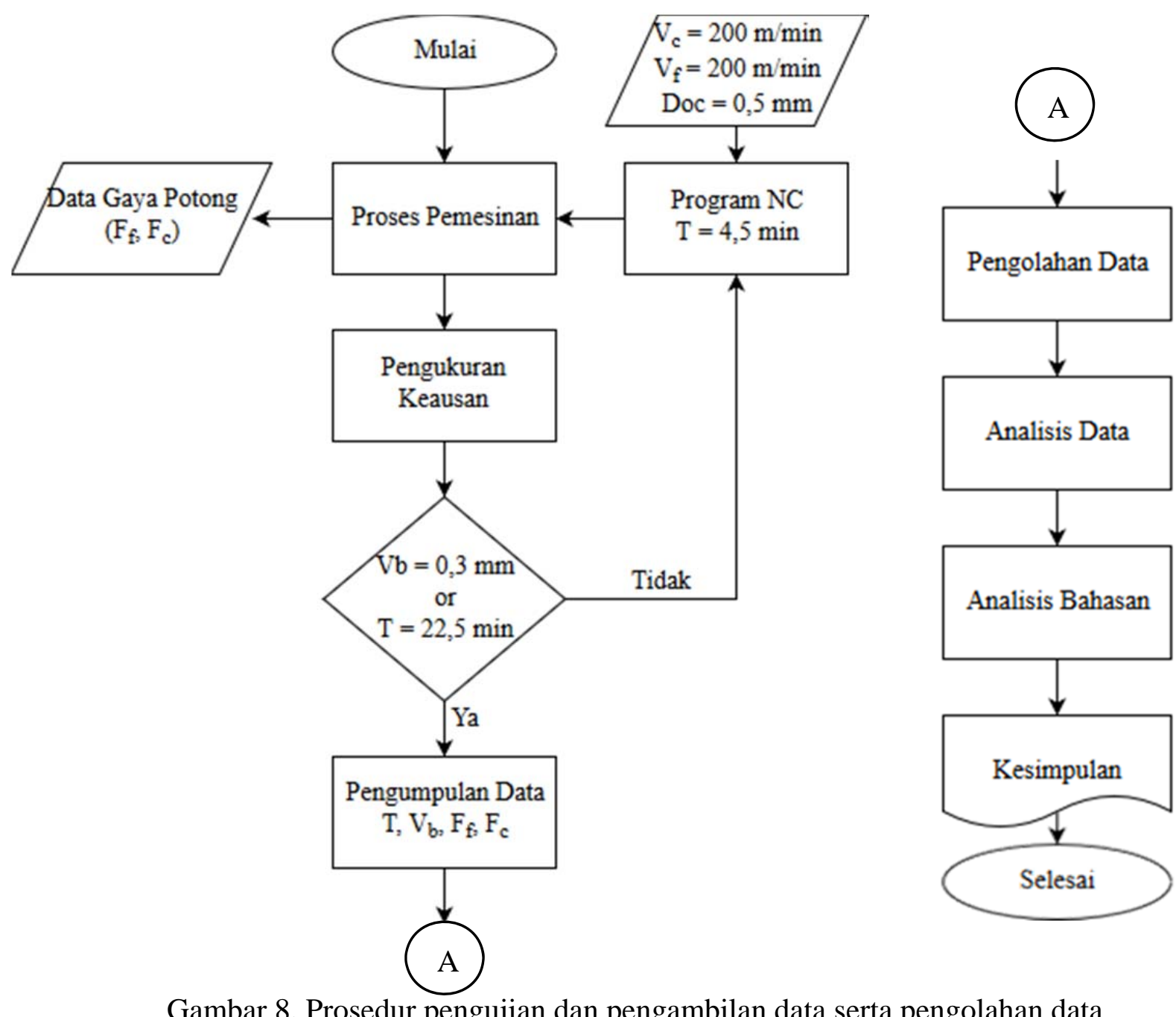

Gambar 8. Prosedur pengujian dan pengambilan data serta pengolahan data 
HASIL PENGUJIAN DAN PEMBAHASAN

Pengaruh Waktu terhadap Keausan Pahat Karbida Coated

Tabel 1. Perbandingan VB setiap kecepatan potong

\begin{tabular}{cccccc}
\hline \multirow{2}{*}{ Keausan (mm) } & \multicolumn{5}{c}{ Waktu } \\
\cline { 2 - 6 } & $\mathbf{4 , 5}$ menit & $\mathbf{9}$ menit & $\mathbf{1 3 , 5}$ menit & $\mathbf{1 8}$ menit & $\mathbf{2 2 , 5}$ menit \\
\hline $\mathrm{VB}(\mathrm{Vc}=200)$ & 0,03 & 0,04 & 0,0625 & 0,075 & 0,09 \\
$\mathrm{VB}(\mathrm{Vc}=180)$ & 0,027 & 0,035 & 0,05 & 0,0675 & 0,09 \\
$\mathrm{VB}(\mathrm{Vc}=160)$ & 0,03 & 0,04 & 0,08 & 0,09 & 0,09 \\
$\mathrm{VB}(\mathrm{Vc}=140)$ & 0,02 & 0,03 & 0,0475 & 0,055 & 0,0675 \\
$\mathrm{VB}(\mathrm{Vc}=120)$ & 0,015 & 0,0275 & 0,0375 & 0,05 & 0,065 \\
\hline
\end{tabular}

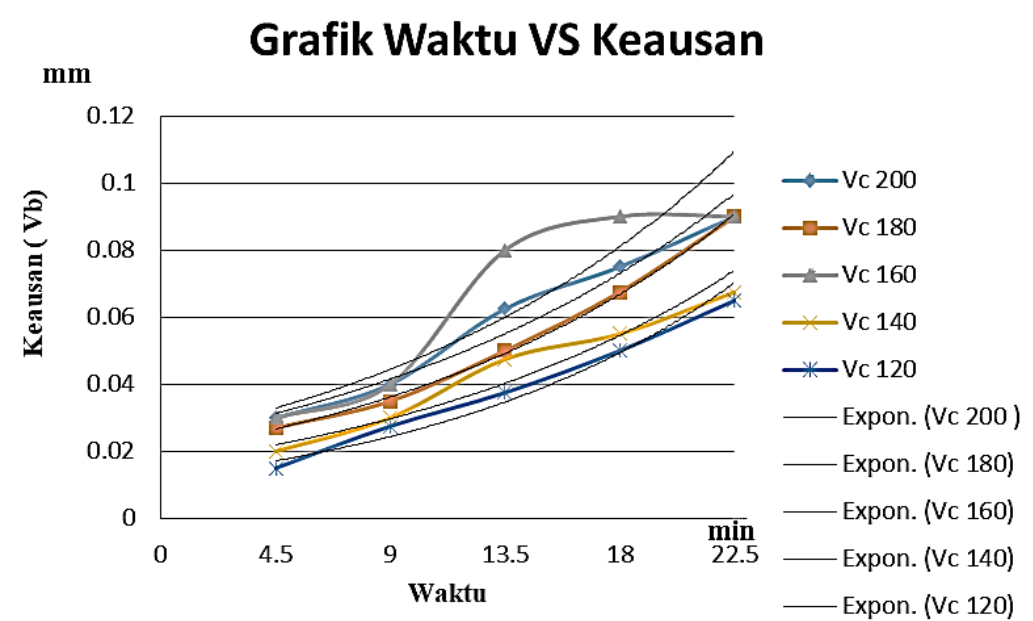

Gambar 9. Grafik waktu terhadap keausan pahat karbida coated

Salah satu faktor keausan terjadi dengan cepat pada kecepatan potong $\left(V_{c}\right)$ karena geram yang dihasilkan berupa geram kontinu. Geram kontinu akan menyentuh rake face terus menerus, sehingga panas dibawa geram berpindah secara konstan ke rake face. Temperatur mata pahat yang tinggi akan merusak mata pahat yang berakibat pada keausan terjadi dengan lebih cepat dan juga kecepatan potong sangat berpengaruh besar terhadap keuasan mata pahat. Berdasarkan Gambar 9 terlihat bahwa kecepatan potong $200 \mathrm{~m} / \mathrm{min}$ pertumbuhan keausan yang terjadi sangat cepat dibandingkan kecepatan potong $120 \mathrm{~m} /$ min yang pertumbuhan keausan terjadi dengan sangat lambat.

\section{Pengaruh Gaya Pemakanan $\left(F_{f}\right)$ terhadap Keausan Pahat}

Tabel 2. Perbandingan VB setiap kecepatan potong

\begin{tabular}{cccccc}
\hline & \multicolumn{5}{c}{ Waktu } \\
\cline { 2 - 5 } & $\mathbf{4 , 5}$ menit & $\mathbf{9}$ menit & $\mathbf{1 3 , 5}$ menit & $\mathbf{1 8}$ menit & $\mathbf{2 2 , 5}$ menit \\
\hline$V B\left(V_{c}=200\right)$ & 0,03 & 0,04 & 0,0625 & 0,075 & 0,09 \\
$F_{f}\left(V_{c}=200\right)$ & 317,78 & 324,67 & 333,56 & 334,78 & 349,78 \\
$V B\left(V_{c}=180\right)$ & 0,027 & 0,035 & 0,05 & 0,0675 & 0,09 \\
$F_{f}\left(V_{c}=180\right)$ & 290,89 & 300,44 & 319,56 & 337,22 & 365,11 \\
$V B\left(V_{c}=160\right)$ & 0,03 & 0,04 & 0,08 & 0,09 & 0,09 \\
$F_{f}\left(V_{c}=160\right)$ & 298,78 & 299,78 & 301,67 & 304,33 & 307,33 \\
$V B\left(V_{c}=140\right)$ & 0,02 & 0,03 & 0,0475 & 0,055 & 0,0675 \\
$F_{f}\left(V_{c}=140\right)$ & 298,89 & 299,78 & 301,78 & 302,56 & 305,22 \\
$V B\left(V_{c}=120\right)$ & 0,015 & 0,0275 & 0,0375 & 0,05 & 0,065 \\
$F_{f}\left(V_{c}=120\right)$ & 286,89 & 292,44 & 294,67 & 297,67 & 299,44 \\
\hline
\end{tabular}

Gaya pemakanan yang dihasilkan dipengaruhi $c$ utting speed yang menyebabkan terjadi perubahan nilai gaya. Melalui eksperimen yang dilakukan, terlihat bahwa setiap penurunan cutting 
speed akan memperkecil besar gaya pemakanan, sehingga dapat dikatakan setiap parameter cutting speed memiliki pengaruh yang berbeda terhadap gaya yang dihasilkan. Gaya pemakanan semakin tinggi maka laju keausan semakin tinggi dan jika gaya makan rendah maka tingkat keuasan pada mata pahat lambat. Luas penampang atau benda kerja juga mempengaruhi dari keausan yang terjadi akibat cutting speed yang di lakukan berbeda, sehingga keausan dapat mempengaruhi dari gaya pemakanan.

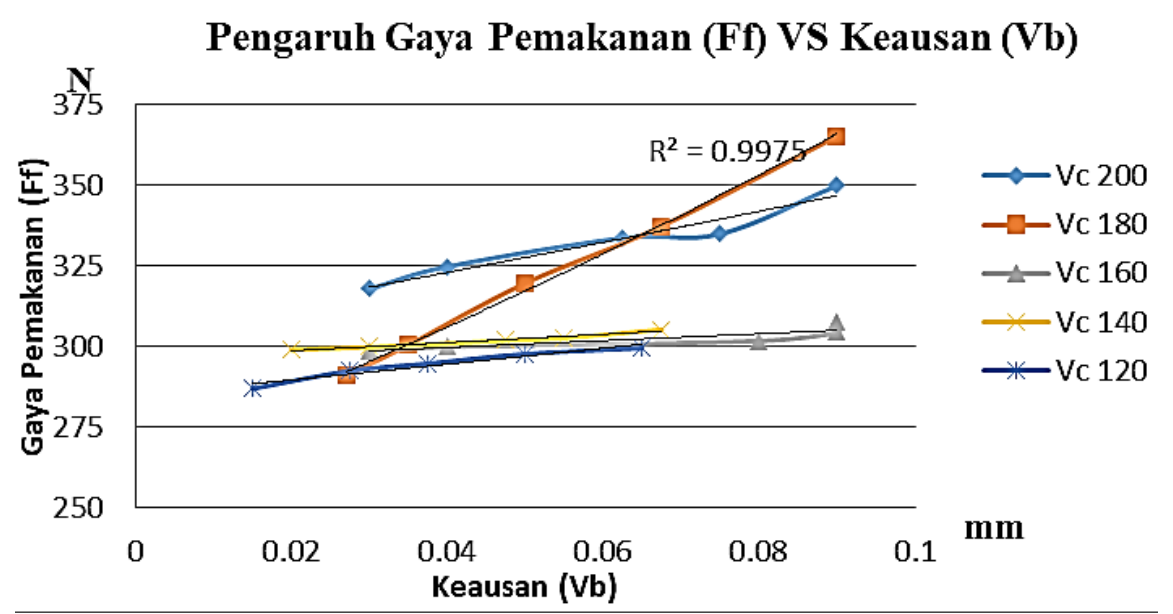

Gambar 10. Grafik gaya pemakanan $\left(F_{f}\right)$ terhadap keausan $(V B)$

\section{Pengaruh Gaya Potong $\left(F_{c}\right)$ terhadap Keausan Pahat}

Tabel 3. Perbandingan VB setiap kecepatan potong

\begin{tabular}{cccccc}
\hline & \multicolumn{5}{c}{ Waktu } \\
\cline { 2 - 5 } & $\mathbf{4 , 5}$ menit & $\mathbf{9}$ menit & $\mathbf{1 3 , 5}$ menit & $\mathbf{1 8}$ menit & $\mathbf{2 2 , 5}$ menit \\
\hline $\mathrm{VB}\left(V_{c}=200\right)$ & 0,03 & 0,04 & 0,0625 & 0,075 & 0,09 \\
$\mathrm{~F}_{\mathrm{c}}\left(V_{c}=200\right)$ & 92,67 & 95,22 & 97,00 & 98,33 & 100,78 \\
$\mathrm{VB}\left(V_{c}=180\right)$ & 0,027 & 0,035 & 0,05 & 0,0675 & 0,09 \\
$\mathrm{~F}_{c}\left(V_{c}=180\right)$ & 89,11 & 89,33 & 91,78 & 92,00 & 92,78 \\
$\mathrm{VB}_{\mathrm{y}}\left(V_{c}=160\right)$ & 0,03 & 0,04 & 0,08 & 0,09 & 0,09 \\
$\mathrm{~F}_{c}\left(V_{c}=160\right)$ & 88,22 & 89,44 & 93,56 & 94,56 & 98,89 \\
$\mathrm{VB}\left(V_{c}=140\right)$ & 0,02 & 0,03 & 0,0475 & 0,055 & 0,0675 \\
$\mathrm{~F}_{c}\left(V_{c}=140\right)$ & 87,78 & 88,44 & 90,00 & 93,89 & 94,22 \\
$\mathrm{VB}\left(V_{c}=120\right)$ & 0,015 & 0,0275 & 0,0375 & 0,05 & 0,065 \\
$\mathrm{~F}_{c}\left(V_{c}=120\right)$ & 81,00 & 82,11 & 85,22 & 87,22 & 88,56 \\
\hline
\end{tabular}

Pengaruh Gaya Pemotongan (Fc) VS Keausan (Vb)

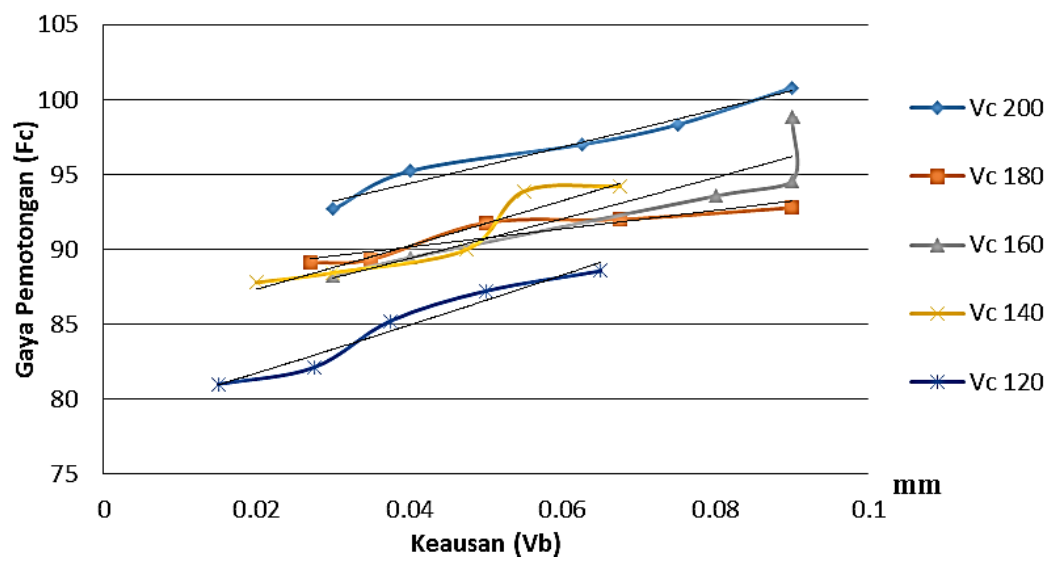

Gambar 11. Grafik gaya pemotongan $\left(F_{c}\right)$ terhadap keausan $(V B)$ 
Gaya potong dipengaruhi cutting speed dan keausan yang terjadi pada mata pahat, sehingga menyebabkan terjadi perubahan nilai gaya potong. Melalui eksperimen yang dilakukan, terlihat bahwa setiap penurunan cutting speed akan memperkecil nilai gaya pemotongan, sehingga dapat dikatakan setiap parameter cutting speed memiliki pengaruh yang berbeda terhadap gaya yang dihasilkan. Gaya pemotongan yang semakin meningkat akibat keausan yang juga semakin meningkat karena ada hubungan korelasi antara gaya potong terhadap keausan yang terjadi. Dapat dilihat pada gambar 11 bahwa ketidakstabilan gaya potong diakibatkan peningkatkan keausan pada ujung sisi mata pahat dan juga diakibatkan dari pengaruh cutting speed.

\section{SIMPULAN}

Mekanisme keausan yang terjadi proses adhesi pada kecepatan potong $200 \mathrm{~m} / \mathrm{min}, 180 \mathrm{~m} / \mathrm{min}$, $160 \mathrm{~m} / \mathrm{min}, 140 \mathrm{~m} / \mathrm{min}, 120 \mathrm{~m} / \mathrm{min}$. Terlihat pada Vc $200 \mathrm{~m} / \mathrm{min}$ terbentuk geram yang kontinu dan terjadi BUE (Build Up Edge).Gaya potong berbanding lurus dengan keausan yang terjadi pada Tabel 2 hingga Tabel 3.

\section{DAFTAR PUSTAKA}

[1]. Afriani. (2012). Proses Pemesinan.Semarang:Universitas Diponegoro

[2]. Kalpakjian, Serope. (1991). Manufacturing Processes for Engineering Materials. Edisi kedua. chicago: Addison Wesley Publishing Company Inc.

[3]. Rochim, Taufiq. (1985). Teori dan Teknologi Proses Pemesinan.Bandung: Jurusan Teknik Mesin, Fakultas Teknik Industri - Institut Teknologi 